\title{
A CASE OF DUPLICATION OF LOWER LIMB, POLYMELIA, CLOACAL OPENING AND HEMIVERTEBRAE
}

\author{
Boddu Praveen Kumar', Sheetal Chepuri², B. Swetha Reddy33
}

${ }_{1}^{1}$ Senior Resident, Department of Paediatrics, ESIC Medical College and Hospital, Sanath Nagar, Hyderabad, Telangana, India. ${ }^{2}$ Senior Resident, Department of Paediatrics, Niloufer Hospital for Women and Children, Hyderabad, Telangana, India. ${ }_{3}^{3}$ Postgraduate Student, Department of Paediatrics, Niloufer Hospital for Women and Children, Hyderabad, Telangana, India.

HOW TO CITE THIS ARTICLE: Kumar BP, Chepuri S, Reddy BS. A case of duplication of lower limb, polymelia, cloacal opening and hemivertebrae. J. Evolution Med. Dent. Sci. 2019;8(24):1966-1968, DOI: 10.14260/jemds/2019/432

\section{PRESENTATION OF CASE}

We report a newborn female baby delivered on $21^{\text {st }}$ March, brought to NICU with deformed lower half of body with an extra lower limb. Polymelia, a congenital anomaly, is the presence of accessory limb. These limbs may be attached to various body regions. Cephalomelia is an extra-limb which is attached to the head. An extra-limb attached to the back bone is called Notomelia. Thoracomelia is an accessory limb arising from the thorax. An extra-limb attached to the pelvis is Pyromelia ${ }^{1}$. The aetiology for these anomalies is varied and they include environmental agents, chromosomal anomalies. We present here a case of polymelia, an accessory limb arising from true pelvis (Pyromelia).

A 1 day old female new born, with birth weight 2900 grams, delivered through Caesarean section was brought to us at 2 hours of life. The mother of the baby was not registered for antenatal check-ups and had no antenatal record. She has no history suggestive of preeclampsia or diabetes or thyroid dysfunction. She has no history of exposure to radiation and teratogenic drugs. She was married to a $3^{\text {rd }}$ degree cousin resulting in a consanguineous marriage.

\section{Physical Examination Findings}

1. Head was normal in size and shape. Eyes, ears, nose, mouth and throat examination did not reveal any abnormalities. [Fig. 1]. Abdomen appears distended.

2. A well-developed extra lower limb is seen arising from the genital area of the pelvis in between the two normal lower limbs. [Fig. 2]

3. A redundant soft tissue on the proximal aspect of accessory limb, Syndactyly of $4^{\text {th }}$ and $5^{\text {th }}$ digits of the extra lower limb.[Fig. 3]

4. Neurological examination was normal on all the three limbs. Labia majora and labia minora are partially developed. [Fig. 4]

5. There is a common passage for urine and meconium, and there is no anal opening. Cloacal opening is evident. [Fig. 5].

6. On radiographic examination there are hemivertebrae in the lumbosacral spine. The extra lower limb had a femur, tibia and fibula. [Fig. 6]

'Financial or Other Competing Interest': None.

Submission 17-04-2019, Peer Review 31-05-2019,

Acceptance 06-06-2019, Published 17-06-2019.

Corresponding Author:

Dr. Boddu Praveen Kumar,

H. No. 14-68/1/7, Divya Homes,

Beeramguda, Hyderabad-502032,

Telangana, India.

E-mail: b.praveen_kumar@yahoo.com

DOI: $10.14260 /$ jemds $/ 2019 / 432$
Systemic examination for cardiovascular system, nervous system and respiratory system did not reveal any abnormality.
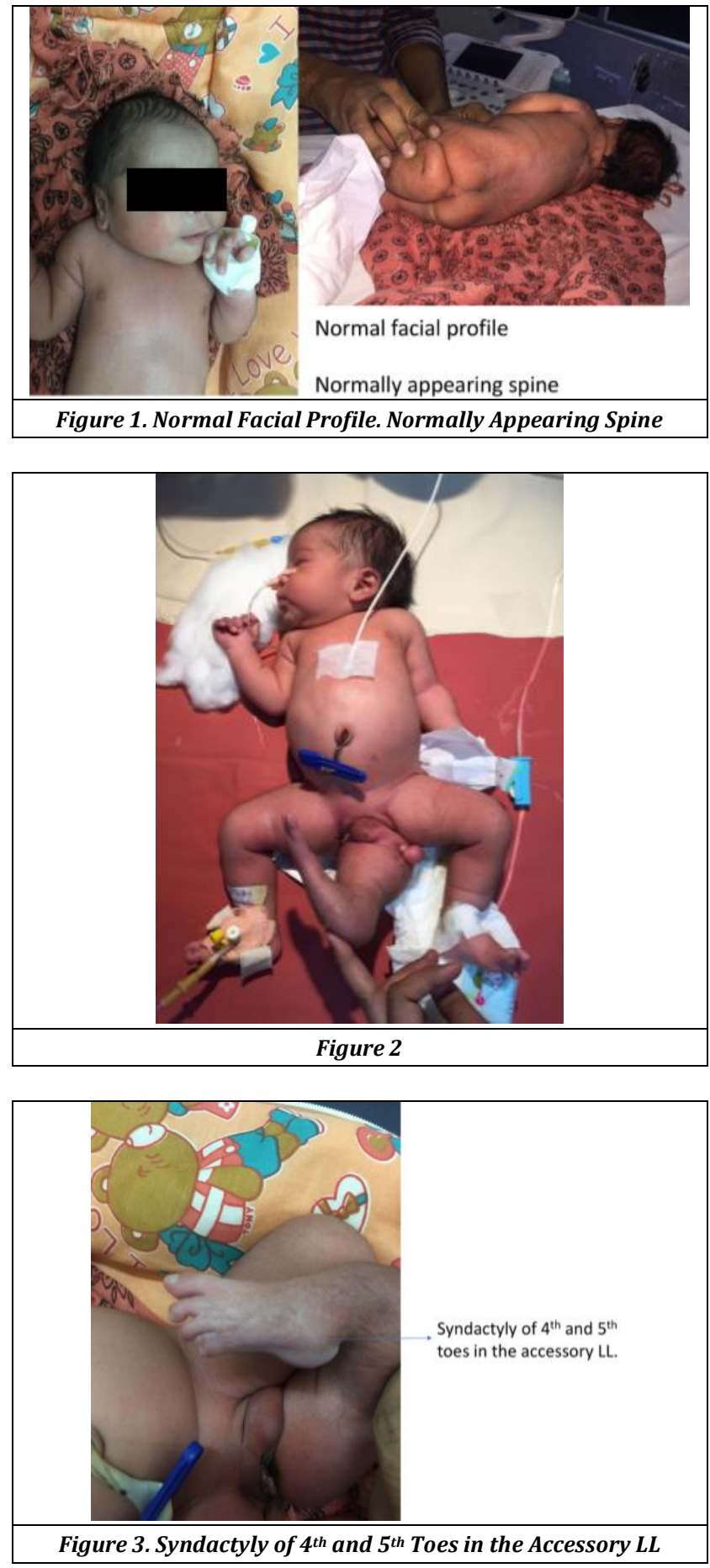

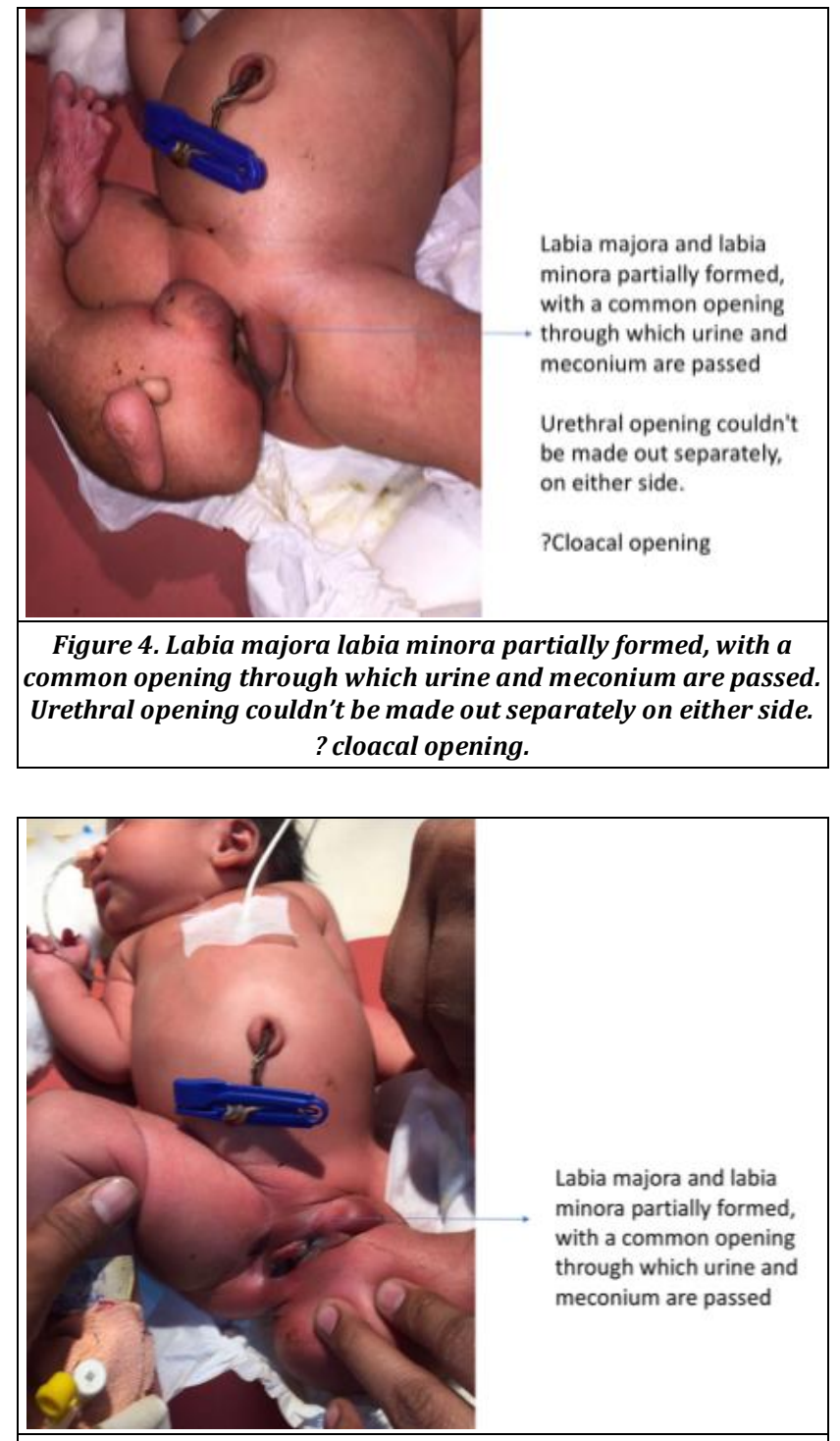

Figure 5. Labia majora and labia minora partially formed, with a common opening through which urine and meconium are passed

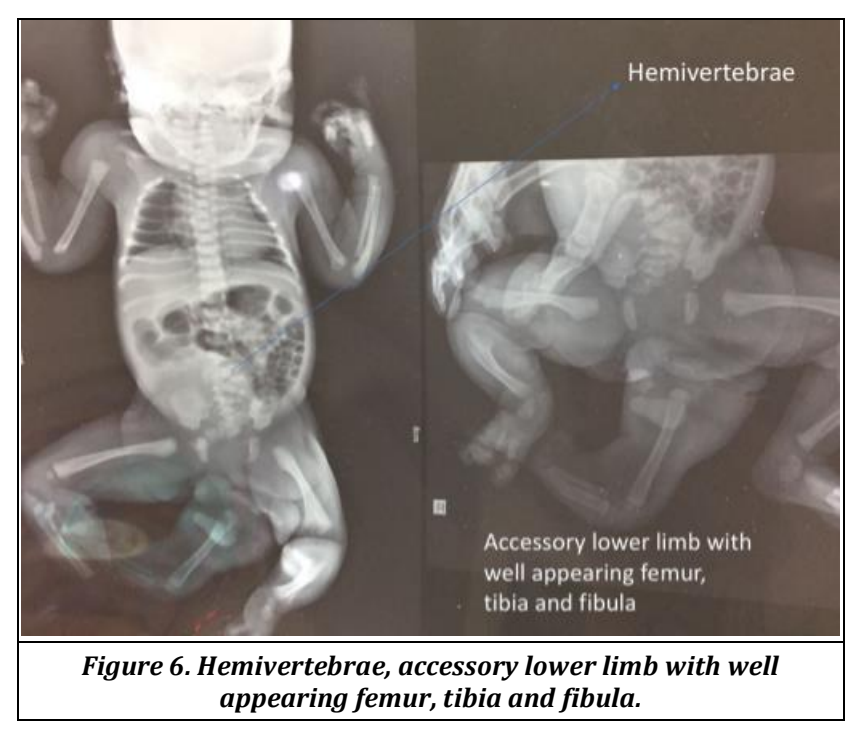

\section{CLINICAL DIAGNOSIS}

Polymelia with associated birth defects, hemivertebrae and cloacal abnormality.

\section{DIFFERENTIAL DIAGNOSIS}

1. Polymelia

2. Parasitic twin.

\section{DISCUSSION}

- Duplication of lower limbs is a known malformation. ${ }^{2}$ It can be either partial or complete duplication.

- They usually have 3 lower limbs, as many as 5 have also been reported. ${ }^{1}$

- Predilection for attachment of the extra limb to sacrum or buttocks.

- The aberrantly attached extra limb usually has abnormal morphology.

They may have sensory or motor or both innervations. Attachment may be into a rudimentary pelvis or directly in to soft tissues of the buttocks. ${ }^{2}$

\begin{tabular}{|c|c|}
\hline Type & Attachment to \\
\hline Cephalomelia & Head \\
\hline Notomelia & Back \\
\hline Pyromelia & Pelvis \\
\hline Thoracomelia & Thorax \\
\hline \multicolumn{2}{|c|}{ Table 1. Polymelia Types } \\
\hline
\end{tabular}

These cases are associated with other anomalies like ${ }^{3}$

- Neural tube defects.

- Hemivertebrae, scoliosis.

- Partial duplication of lower genitourinary and GI structures.

- Ipsilateral renal agenesis. ${ }^{1}$

- These anomalies are caused by various adverse influences in embryonic life. $., 5,6,7$

Between the 4th and 5th weeks of development, the limb differentiation occurs. ${ }^{8}$ Limb differentiation occurs from dorsal to ventral and from proximal to distal pattern. ${ }^{6,7}$ In the beginning, anterior and posterior pairs of limb buds arise from either side of embryo. These limb buds contain ectodermal and mesodermal elements. Limb differentiation and cell positioning is a result of mesenchymal and ectodermal interaction. The ectodermal layer over the limb bud is referred to as the apical ectodermal ridge (AER). Another group of cells underlying the AER is the zone of proliferating activity (ZPA). ZPA and AER are required for limb development.9,10 AER helps in maintaining ZPA. Mesodermal cells in ZPA stimulates formation of AER. The approximate timing of teratogenic event can be determined by the level and manifestations of the limb deformation. As the AER grows more distal, the induced mesoderm cells, comprising rudimentary parts of the limb, can continue to grow without any developmental interference even if the AER is transplanted to the adjacent region. This could mean that the influence of the AER with abnormal splitting leads to duplication of limbs.11,12 These anomalies may be a result of several factors. Thalidomide is one of the major teratogens that leads to limb defects. These defects could be amelia (Absence of limb) or phocomelia (Absence of proximal limb elements) and loss of a thumb or tip of a digit. Structural limb anomalies are also known to occur with women taking hormones like progesterone. Antenatal surveillance helps in early detection of such anomalies. 
Cloacal abnormality, ${ }^{13}$ occurring in approximately 1 in 400, 000 births, the remarkable similarity among otherwise normal individuals with this bizarre type of defect suggests a similar mode of developmental pathology having its inception as a single localized defect, during early mesodermal development, which contribute to cloacal septum, infraumbilical mesenchyme and caudal vertebrae. This leads to-

1. failure of cloacal septation, with the persistence of a common cloaca into which the ureters, ileum, and a rudimentary hindgut open;

2. complete breakdown of the cloacal membrane with exstrophy of the cloaca, failure of fusion of the genital tubercles and pubic rami, and often omphalocele; and

3. incomplete development of the lumbosacral vertebrae with herniation of a grossly dilated central canal of the spinal cord (hydromyelia), yielding a soft, cystic, skincovered mass over the sacral area, sometimes asymmetric in its positioning. ${ }^{14}$

Affected female infants have unfused mullerian elements with bifid uterine horns and short, duplicated, or atretic vaginas. ${ }^{15}$ The term OEIS complex (Omphalocele, cloacal exstrophy, imperforate anus, and spinal defects) is an acronym to indicate the common defects associated with cloacal exstrophy. 13

\section{DISCUSSION OF MANAGEMENT}

Treatment for cases like ours includes a surgery to amputate the accessory limb from the true pelvic region. The management of cloacal defects includes several procedures aimed at restoring the anal canal by anal transposition, posterior sagittal anorectoplasty.13 Management of hemivertebrae for future possibility of scoliosis depends on case to case basis. Radiological assessment plays a crucial role in patients with polymelia to assess for other congenital anomalies before surgical intervention. The child was successfully operated, and the lower limb was amputated, and a colostomy was performed.

\section{FINAL DIAGNOSIS}

Duplication of Lower Limbs, Pyromelia, Ambiguous Genitalia with Cloacal Opening and Intestinal Obstruction.

\section{REFERENCES}

[1] http://www.academia.edu/29030427/Three_new_cas es_of_disorganizationlike_syndrome_One_with_access ory_extrophia_vesicalis.

[2] Roger SE, Judith GH. Human malformations and related anomalies. $2^{\text {nd }}$ edn. New York: Oxford University Press 2006.
[3] Verma S, Khanna M, Tripathi VN, et al. Occurrence of polymelia in a female child. J Clin Imaging Sci 2013;3:18.

[4] Griffet J, Bastiani-Griffet F, Jund S, et al. Duplication of the leg - renal agenesis: congenital malformation syndrome. J Pediatr Orthop B 2000;9(4):306-8.

[5] La Torre R, Fusaro P, Anceschi MM, et al. Unusual case of caudal duplication (dipygus). J Clin Ultrasound 1998;26(3):163-5.

[6] Kher AS, Gahankari DR, Tambwekar SR, et al. Supernumerary limbs: a case report of a rare congenital anomaly. Ann Plast Surg 1996;37(5):54952.

[7] Kojima T, Hirakawa M, Hirase Y, et al. Complete congenital duplication with incomplete separation of a lower extremity. Plast Reconstr Surg 1993;91(5):9269.

[8] O'Rahilly R, Muller F. Developmental stages in human embryos, including a revision of Streeter's "Horizons" and a survey of the Carnegie collection. Washington, DC: Carnegie Institution of Washington, Publication No. 637, 1987.

[9] Roberts DJ, Tabin C. The genetics of human limb development. Am J Hum Genet 1994;55(1):1-6.

[10] Scherz PJ, Harfe BD, McMahon AP, et al. The limb bud Shh-Fgf feedback loop is terminated by expansion of former ZPA cells. Science 2004;305(5682):396-9.

[11] Packard DS Jr, Levinsohn EM, Hootnick DR. Extent of duplication in lower-limb malformations suggests the time of the teratogenic insult. Pediatrics 1993;91(2):411-3.

[12] Zhao L, Li MQ, Sun XT, et al. Congenital lumbosacral limb duplication: a case report. J Orthop Surg (Hong Kong) 2006;14(2):187-91.

[13] Jones KL, Jones MC, Del Campo M. Smith's recognizable patterns of human malformations. 7 th edn. Elsevier Publication 2015: p. 814.

[14] Feldkamp ML, Botto LD, Amar E, et al. Cloacal exstrophy: an epidemiologic study from the International Clearinghouse for Birth Defects Surveillance and Research. Am J Med Genet C Semin Med Genet 2011;157(4):333-43.

[15] Hurwitz RS, Manzoni GA, Ransley PG, et al. Cloacal exstrophy: a report of 34 cases. J Urol 1987;138(4 Pt 2):1060-4. 